Document downloaded from:

http://hdl.handle.net/10251/32095

This paper must be cited as:

Margot, XM.; Hoyas Calvo, S.; Fajardo, P.; Patouna, S. (2011). CFD Study of Needle Motion Influence on the Spray Conditions of Single-Hole Injectors. Atomization and Sprays. 21(1):31-40. doi:10.1615/AtomizSpr.v21.i1.30

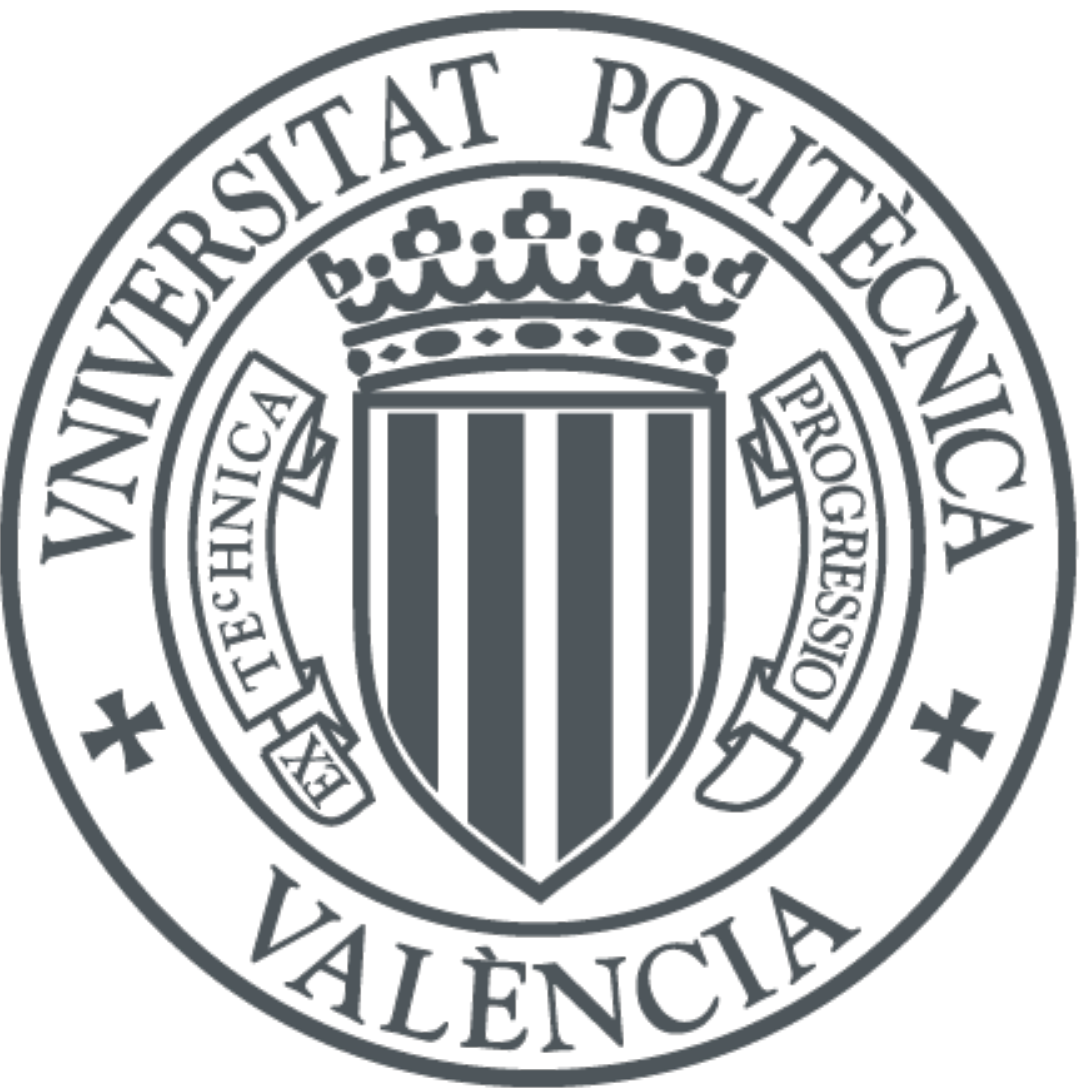

The final publication is available at

http://www.dl.begellhouse.com/download/article/4c00a225548a5573/AAS2101-2618.pdf

Copyright Begell House

Additional Information 


\title{
CFD Study of Needle Motion Influence on the Spray Conditions of Single-Hole Injectors
}

\author{
X. Margot, S. Hoyas, P. Fajardo and S. Patouna* \\ CMT - Motores Térmicos, Universidad Politécnica de Valencia \\ Camino de Vera S/N, 46022 Valencia
}

\begin{abstract}
The spray characteristics and consequently the success of the diesel combustion process is strongly affected by the manner in which fuel is introduced in the combustion chamber. This work consists in studying the effect of needle motion of typical single-hole sac-type injectors on nozzle exit conditions. Three-dimensional moving mesh simulations have been carried out to calculate the injection process using cylindrical and conical nozzle geometries. The CFD analysis includes a study of the effect of cavitation on kinetic turbulent energy and velocity profiles. Results show that the flow within the nozzle and at the exit varies depending on the nozzle geometry and needle position. The model predicts clouds of cavitation that grow and exit the nozzle at low needle lifts. A kind of hysteresis in the development of the flow has also been observed between needle opening and closing. The existing correlation between turbulence and cavitation at the nozzle hole exit during the needle motion has been quantified.
\end{abstract}

\section{Introduction}

When considering engine fuel injection systems, such as multi-hole Diesel injectors, the internal nozzle flow characteristics such as the turbulence level and distribution, the cavitation pattern and the velocity profile are known to affect significantly the air-fuel mixture in the spray [1-5]. Experimental investigations of sprays are often done with single-hole injectors, to be able to study in detail the spray evolution, avoiding the extra complexity of sprays interactions. Yet, observations have shown that the spray characteristics of a single-hole nozzle are different from those of a multi-hole nozzle [6-9]. Hence, the extrapolation of the results of single-hole to multi-hole should be done with careful consideration.

Other factors, such as the geometry of the nozzle, which may be either conical or cylindrical, influence the internal flow significantly and can affect the injection rate and spray atomization [6]. The needle movement, which imprints a highly transient character to the internal flow is another important factor that can affect the fuel atomization [10]. In this context, it is useful to understand in what way the cavitation inside the nozzle is caused or enhanced by the nozzle geometry and needle lift and how this affects the spray characteristics.

Considering the very small size of the Diesel injectors, it is very difficult, not to say impossible, to study experimentally the flow inside. Hence, modeling of the internal flow represents an attractive alternative. Previous numerical studies, where conical and cylindrical nozzle geometries have been studied for a wide range of Reynolds and cavitation numbers, have revealed a clear correlation between cavitation and geometry [6, 11-13]. However, most of these studies consider two-dimensional, simplified real injector geometries, and neglect needle lift conditions. Some studies of multi-hole nozzle injectors have also been performed with consideration of the needle movement in order to study the effect of the transient opening/closing of the needle valve on the cavitating flow distribution [10, 14-18]. However, since many experiments are made for single-hole configurations, it is still important to gain knowledge about the dynamic behavior of the cavitation pattern and its effect on the flow at the exit for this type of injector.

The present work deals with the 3D modeling of single-hole Diesel injectors in which the influence of needle motion on the nozzle exit characteristics is evaluated. Two sac-type injectors have been compared, one with a cylindrical and the other with a conical orifice, positioned in line with the nozzle axis. The real size geometries have been reproduced, in order to obtain an accurate description of the geometrical details that can be determinant for the inception of cavitation. Transient CFD calculations with moving mesh have been carried out with a finite-volume based commercial code [19] to simulate the flow inside the nozzle considering the needle movement in realistic engine conditions. The resulting flow features are analyzed in cavitating and non cavitating conditions as predicted by the computational model.

The following section briefly presents the CFD approach highlighting important aspects of the nozzle characterization and model inputs, while the last section discusses the most significant results.

* Corresponding author: stapa1@mot.upv.es 


\section{Injector flow modelling}

\section{Geometric characterization of the nozzles}

Since the internal geometry of the injector is known to affect significantly the flow inside the nozzle as well as at the exit, it is important to characterise well this geometry and to reproduce it as best as possible for the calculations.

The injector is of the sac-type with a single hole positioned in line with the nozzle axis, as seen in the sketch of Figure 1.

This simple geometry is of interest: it is frequently used in spray investigations because it facilitates the experimental procedure and helps in the clarification of the flow phenomena. A silicone mould technique has been used [20] to characterise the exact geometry of the hole and a representative image of the mould is presented in Figure 2. The main geometric data of the nozzles is measured using a microscope with special computer aided design software. This measurement technique has been used successfully in the study of the Diesel nozzle internal flow, to provide experimental as well as numerical insight in the influence of the internal geometry on the flow characteristics and the subsequent spray behavior [4, 13]

Two nozzle shapes have been investigated: a cylindrical nozzle and a conical nozzle of dimensions shown in Table 1 . The k-factor, defined in equation 1 defines the exact conicity of the nozzle.

$$
K-\text { factor }=\frac{D_{i}-D_{o}}{10}
$$

\section{Numerical methodology}

The nozzle flow simulations were realized with a finite-volume commercial code [20] in transient conditions including the moving mesh of the needle. Due the symmetry of the injector with respect to its axis, a $90^{\circ}$ sector was meshed as illustrated in the images of Figure 3. The sac and the hole were meshed with a fine grid (cell size: $10 \mu \mathrm{m}$ ); the moving mesh part between the needle and the injector body was generated with coarser cells that expanded or contracted with the needle movement. The total number of cells was about 70000 . The true geometry displacement or lift law was reproduced in the calculations by a strategy explained in detail in [21]. It should be noted that a grid independence study was performed before adopting the final mesh described above. The maximum lift considered was $250 \mu \mathrm{m}$ and the minimum $15 \mu \mathrm{m}$, as the code cannot calculate cells with size zero.

Symmetry boundaries were defined to model the geometric symmetry of the injector and constant pressure was prescribed at both the inlet and outlet. The duration of the injection cycle was fixed as $1 \mathrm{~ms}$, as is usual in the experiments and in the real operating conditions, and the time step was set to $5.0 \times 10^{-7} \mathrm{~s}$ in order to enhance temporal accuracy.

All calculations presented here were made using the k-epsilon/low Reynolds number turbulence model with hybrid near wall treatment. The solver is based on the pressure correction method and uses the SIMPLE algorithm. In terms of discretization the MARS scheme was used for the momentum equations and the upwind differencing scheme for the $\mathrm{k}-\varepsilon$ turbulence model equations.

The cavitation model is based on the Rayleigh equation, which links the rate of change of the bubble radius with the local pressure. In this model, both the liquid and vapour densities are constant and there is no slip between bubbles and liquid. The liquid fuel density is $828 \mathrm{~kg} / \mathrm{m}^{3}$, its molecular viscosity $2.14 \times 10^{-3} \mathrm{~kg} / \mathrm{ms}$. The corresponding values for the vapour are, respectively, $0.025 \mathrm{~kg} / \mathrm{m}^{3}$ and $1 \times 10^{-5} \mathrm{~kg} / \mathrm{ms}$. The initial seed bubble radius was set to $1.0 \times 10^{-6} \mathrm{~m}$ and the nuclei number density to $1.0 \times 10^{14}$, in agreement with values proposed in the literature for real-size nozzle simulations [22-23]. Further details of the model used may be found in [19, 24].

\section{Results and discussion}

\section{Needle motion influence on flow pattern}

Representative images of the predicted vapour volume fraction, the turbulence kinetic energy and the velocity field are presented in Figure 4 for the conical and the cylindrical nozzle at full lift. The calculations of the flow characteristics were performed at real engine operating conditions: injection pressure $=141 \mathrm{MPa}$ and back pressure $=1 \mathrm{MPa}$. Figure 4 shows that even at these critical conditions, the conical nozzle does not cavitate. For both nozzles, when the liquid enters into the injection hole, the velocity increases rapidly due to the decrease of cross sectional area. The highest velocity gradients are confined to the entrance area of the nozzles where the lowest pressures are also expected. The flow acceleration is more gradual in the conical nozzle than in the cylindrical. For both nozzles, the turbulence kinetic energy is enhanced at the hole inlet and diffuses towards the nee- 
dle exit. This has also been observed in the literature with other cavitation models [25], but has been attributed to the bubble break-up process which takes place along the hole length.

However, the turbulence level in the conical hole inlet and along the nozzle is lower. One reason for this difference may be linked to the hole inlet smoother curvature (R88 instead of R45 for the cylindrical nozzle), as well as to the greater inlet diameter of the conical nozzle (D176 instead of D157 for the cylindrical nozzle). This was confirmed by comparing results of the two nozzles under non cavitating flow conditions (1500/100 bar). Another reason is the absence of cavitation in the conical nozzle.

Representative images of the cavitation distribution during the needle motion are presented in Figure 5, limited to the cylindrical nozzle, since no cavitation appears in the conical nozzle. They show that the cavitation at all needle lifts develops in form of a vapour film confined to the periphery of the nozzle, in agreement with observations by $[1,26]$. The extension of the cavitation bubble grows with the needle lift. However, there is a kind of hysteresis between the needle valve opening and closing particularly at low needle lifts: it is clearly visible in Figure 5 for $25 \mu \mathrm{m}$ that the vapour does not reach the nozzle exit at valve opening, while it does at valve closing. This shows that the influence of the needle lift position on the development of cavitation is more important when the needle ascends. On the contrary, during the needle closing the cavitation seems less transient, it takes longer to recede back.

Figure 6 shows the evolution of the cavitation bubble close to the nozzle exit while the needle is descending. It is interesting to note that the cavitation level attains its peak at $1650 \mu \mathrm{s}$, and then suddenly decreases between this instant and $1660 \mu \mathrm{s}$. This illustrates the fact that the cavitation cloud grows and exits the nozzle periodically. When it grows all the area is occupied by vapour, but just seconds later the area is occupied mainly by liquid as the vapour cloud has been evacuated. This phenomenon may be linked to the highly transient nature of the cavitating flow.

There is some asymmetry in the cavitation pattern, especially after the evacuation is observed. This could probably be attributed to numerical differences caused by either CAD imperfections or by some inherent asymmetry of the nozzle grid [27]. However, it only occurs when the cavitation level is low and does not affect significantly the solution. Moreover, since the real injector geometry is not perfectly symmetric [20], it is reasonable to assume that the real physical flow would not be symmetric either, so that this may be a more physical representation of the flow.

\section{Needle motion influence on spray conditions}

The interest of the presented calculations and results is to derive from the nozzle internal flow conditions information for the boundary conditions of the spray calculation. Though the spray calculation itself is beyond the scope of this paper, a further analysis of the internal nozzle flow results at the exit section yields important information, in terms of injection rate, velocity, turbulence and cavitation, as shown in Figure 7 for both the cylindrical and the conical nozzles. The same lift law based on simple linear equations [21] was used for the cylindrical and conical nozzle calculations.

As seen in Figure 7, top left, the quantity of injected fuel is less in the case of the cylindrical nozzle than in the conical nozzle, due to the smaller inlet diameter and the presence of cavitation. Additionally, the cavitation has the effect of decreasing the exit area and consequently increasing the exit velocity (velocity magnitudes curve, top right).

In terms of evolution during the needle motion, the CFD results clearly show that the mass flow rate increases greatly with increasing needle lift until a certain value, as would be expected. However, very quickly, the mass flow rate becomes independent of the lift. This effect is also noticeable in the evolution of the velocity at the exit. It indicates that the maximum mass flow rate and velocity are limited by the nozzle inlet section conditions.

The turbulence kinetic energy, however, changes noticeably with the needle movement (Figure 7, bottom left). It is created at very low needle lifts $(<50 \mu \mathrm{m})$, during both opening and closing, independently of whether there is cavitation or not. This is due to the restricted area in the annulus between needle and nozzle body, so that locally the liquid accelerates, increasing the turbulence level. The TKE attains its maximum level when the mass flow rate and velocity stabilise at their maximum value (between 50 and $75 \mu \mathrm{m} \mathrm{lift}$ ). Then the turbulence level decays significantly and stabilises at high needle lifts (over $150 \mu \mathrm{m}$ ), and increases again when the needle descends below $150 \mu \mathrm{m}$. The fast turbulence dissipation coincides with the disappearance of the mean velocity gradients and it is interesting to note that the renewed increase at needle closing (between $150 \mu \mathrm{m}$ and $50 \mu \mathrm{m}$ ) is more important in the conical nozzle, so that the TKE level is the same in both nozzles just before needle closing. This seems to indicate that the generation of cavitation in the cylindrical nozzle tends to absorb part of the turbulence generated during the needle motion.

This may be confirmed when observing the evolution of the volume fraction of vapour during lift motion (Figure 7, bottom right). The maximum level of TKE coincides with the onset of cavitation at approximately 50 $\mu \mathrm{m}$ lift; then with further lift opening $(50 \mu \mathrm{m}$ to $150 \mu \mathrm{m})$, the quantity of vapour initially oscillates and gently increases up to the moment the fully developed cavitating regime is attained, at relatively high lift $(150 \mu \mathrm{m})$. The 
level of TKE decreases during this exact period, at a slightly faster rate than in the non-cavitating case. In addition, while the level of cavitation remains stable, so does the level of turbulence. Furthermore, the sudden growth of the vapour cloud observed at needle closing $(1650 \mu \mathrm{m}$, see Figure 6 , and the peak of volume fraction in Figure 7 , bottom right) just before its release coincides with the period when the needle reaches low lifts and the TKE renewed generation is lower than in the non-cavitating case.

It seems that at low needle lifts, the vapour bubble is more unstable due to the increased flow turbulence caused by the restricted flow passage. At high lifts, it is fairly stable.

Another interesting point is that there is a kind of hysteresis between needle opening and closing (Figure 7 bottom). The process of needle opening seems to generate more turbulence than the needle closing and this is independent of the nozzle geometry, and of the presence of cavitation.

Moreover, the hysteresis is also visible in the cavitation evolution: there is significantly more vapour reaching the nozzle exit when the needle descends. This may be explained as follows: since at full lift, the cavitation is fully developed, the increase in turbulence caused by the closing of the needle enhances further the generation of cavitation. This seems to confirm that part of the turbulence serves to feed the generation of cavitation, when there is cavitation.

However, it is the needle motion at low lifts, which enhances the turbulence level and, the cavitation absorbs part of the turbulence kinetic energy to grow. This has to be taken into account when analyzing the flow characteristics at the nozzle exit and setting up boundary conditions for the spray calculations.

\section{Conclusions}

The purpose of this study was to gain knowledge about the influence of nozzle geometry and needle lift on the characteristics of the flow at the exit of the nozzle, in order to provide information for spray calculations. The needle lift motion was taken into account using CFD moving mesh calculations. Two sac-type single-hole injectors, one conical and one cylindrical have been modelled and selected results of the ongoing investigation have been presented. The main conclusion remarks are noted below:

- As is already known, the shape of the nozzle greatly affects the onset of cavitation. Indeed, no cavitation appears in the convergent nozzle, independently of the highly transient nature of the flow.

- In the cylindrical nozzle, the cavitation develops in form of a vapour film attached to the wall and its extension varies depending on the needle lift.

- The model predicts clouds of cavitation growing and evacuating the nozzle at low needle lifts, which is in accordance with the highly transient nature of the flow during needle motion.

- The presence of cavitation in the nozzle accelerates significantly the flow at the exit of the nozzle, which in turn enhances the turbulence level within the hole.

- However, the turbulence kinetic energy is mainly created in the first stages of needle opening and in the last stage of closing, independently of whether there is cavitation or not. This is probably due to the local acceleration of the flow at the nozzle inlet caused by the restricted passage. As the inlet area grows, the turbulence level decays significantly and stabilises at high needle lifts (over $150 \mu \mathrm{m}$ ), and increases again when the needle descends below $150 \mu \mathrm{m}$, though to a lesser extent.

- The needle motion creates a kind of hysteresis, which is visible in the turbulence kinetic energy evolution, independently of the presence of cavitation, as well in the development of cavitation.

In conclusion, it is important to take into account the needle motion, since its effect is determinant to characterise the flow at the nozzle exit and provide boundary conditions information for spray calculations.

The needle motion is mainly responsible for the creation of the turbulence kinetic energy that reaches the nozzle exit. In fact, at low lifts, during opening and closing, turbulence is enhanced; at high lifts, it is minimum. This is always the case, whether there is cavitation or not.

However, it is clear that in the presence of cavitation, the turbulence kinetic energy level is higher, probably due to the higher flow velocity at the nozzle exit. Furthermore, the development of cavitation seems to be linked somehow to the turbulence level. Indeed, it seems that part of the turbulence kinetic energy is being absorbed during the growth of the cavitation bubble.

This information is valuable when considering boundary conditions for the spray calculations. It is generally assumed that cavitation enhances the turbulence, since it reduces the outlet effective area. However, the study presented here tends to prove that cavitation growth absorbs part of the turbulence kinetic energy generated during the needle motion. It is important to note that in the frame of this work, even at critical cavitation conditions, the volume fraction was of the order of $25 \%$. It may be inferred that at higher cavitation levels, when the bubble growth is more important, the process may absorb more turbulence kinetic energy.

In any case, the results presented above prove that the needle motion has a considerable effect on the emerging fuel turbulence level. 


\section{Acknowledgements}

This research has been funded by the Spanish Government in the frame of the Project "Caracterización experimental de la cavitación en el flujo interno e influencia sobre modelos de chorro Diesel", Reference TRA2007-68006-C02-01. SH and PF were partially supported by the Universidad Politécnica de Valencia under the program "Primeros Proyectos de investigación", in the frame of the project "Simulación CFD de chorros Diesel en inyección directa: la atomización primaria", Reference PAID-2759 and by the Generalitat Valenciana under contract GV/2010/039.

\section{References}

[1] Soteriou C., Andrews R. and Smith M., Direct Injection Diesel Sprays and the Effect of Cavitation and Hydraulic Flip on Atomization, SAE paper 950080, 1995.

[2] Bergwerk W., Flow Pattern in Diesel Nozzle Spray Holes, Proc. Inst. Mech. Engrs 173:665-660 (1959).

[3] Sazhin S.S., Feng G., and Heikal M.R., A Model for Fuel Spray Penetration. Fuel 80:2171-80 (2001).

[4] Payri F., Bermúdez V., Payri R., and Salvador F.J., The Influence of Cavitation on the Internal Flow and the Spray Characteristics in Diesel Injection Nozzles. Fuel 83:419-31 (2004).

[5] Su, T. F., Farell, P. V. and Nagarajan, R.T., Nozzle Effect on High Pressure Diesel Injection, SAE paper 950083, 1995.

[6] Han J. S., Lu P-S., Xie X. B., Lai M. C. and Henein N. A., Investigation of Diesel Spray Primary Break-up and Development for Different Nozzle Geometries, SAE Paper 2002-01-2775, 2002.

[7] Fujimoto, H., Tanabe, H., Kuniyoshi, H., and Sato, G. T., "Investigation on the Characteristics of Diesel Spray (Shape of Multiple Diesel Sprays and Air Movement between Neighboring Sprays)," Bulletin of JSME 25, No. 200 (1982).

[8] Xu, M., and Hiroyasu, H., Development of a New Optical Technique for Measuring Diesel Spray Penetration, SAE paper 902077, 1990.

[9] Arcoumanis C., Cossali E., Paal, G. and Whitelaw J. H., Transient Characteristics of Multi-Hole Diesel Sprays, SAE paper 900480, 1990.

[10]Payri F., Margot X., Patouna S., Ravet F. and Funk M., A CFD Study of the Effect of the Needle Movement on the Cavitation Pattern of Diesel Injectors, SAE paper 2009-24-0025, 2009.

[11]Sarre von Kuensberg C., Kong S.C. and Reitz R. D, Modeling the Effects of Injector Nozzle Geometry on Diesel Sprays, SAE paper 1999-01-0912, 1999.

[12]Macián V., Payri R., Margot X., and Salvador F.J, A CFD Analysis of the Influence of Diesel Nozzle on the Inception of Cavitation. Atomization and sprays 13:579-604 (2003).

[13]Payri R., Margot X. and Salvador F.J, A Numerical Study of the Influence of the Diesel Nozzle Geometry on the inner Cavitating Flow, SAE paper 2002-01-0215, 2002.

[14]Michels. U, Krüger C, König G, Blessing M, Schwarz V, Merker G. P, “Analysis of the Influence of the Injection Strategy on Cavitating Nozzle Flow, Spray Formation and combustion in a Heavy Duty Truck engine. Effects on Spray and Mixture Formation", THIESEL 2004 Conference on Thermo- and FluidDynamic Processes in Diesel Engines, Valencia, September 2004.

[15]Gavaises M., Papoulias D., Giannadakis E., Andriotis A., Mitroglou N. and Theodorakakos A., "Comparison of cavitation formation and development in Diesel VCO nozzles with cylindrical and converging tapered holes", THIESEL 2008 Conference on Thermo- and Fluid-Dynamic Processes in Diesel Engines, Valencia, Valencia, September 2008.

[16]Lee J. W., Min K..D., Kang K. Y., Bae C. S., Giannadakis E., Gavaises M., and Arcoumanis C., Effect of Piezo-driven and Solenoid-driven Needle Opening of Common-rail Diesel Injectors on Internal Nozzle Flow and Spray Development. Engine Research 7:489-502 (2006).

[17]Du H., Liu J., and Tang J., A CFD Investigation on the Nozzle Orifices Distributing in Different Space Layers, SAE paper 2008-01-0948, 2008.

[18]Nagaoka M., Ueda R., Masuda R., von Berg E. and Tatschl R. "Modeling of Diesel Spray Atomization Linked with Internal Nozzle Flow", THIESEL 2008 Conference on Thermo- and Fluid-Dynamic Processes in Diesel Engines, Valencia, September 2008.

[19]STAR-CD Methodology, version 4.06, CD adapco, 2008

[20]Macián V., Bemudez V., Payri R., and Gimeno J., New Technique for the Determination of the Internal Geometry of Diesel Nozzle with the Use of Silicone Methodology, Experimental Techniques 27:39-43 (2003).

[21]Margot X., Hoyas S., Fajardo P., Patouna S., Moving mesh generation strategy solving an injector internal flow problem, Mathematical and Computer Modelling, Mathematical and Computer Modelling (2010), doi:10.1016/j.mcm.2010.03.018

[22]Yuan W., Sauer J., and Schnerr G.H., Modeling and computation of unsteady cavitation flows in injection nozzles, 1st International Colloquium on Microhydrodynamic, Paris, France, 2000. 
[23]Yuan W., and Schnerr G.H., Cavitation in injection nozzles-Effect of injection pressure fluctuations. Proc CAV2001, Fourth International Symposium on cavitation. Pasadena, California, USA, 2001.

[24]Kurtsman E. D., Rayleigh Equation for the Growth of a Gas Bubble under Conditions of Finite Liquid Volume, Engineering Physics and Thermophysics 14, Nr. 1 (1968).

[25]Roth H., Gavaises M., and Arcoumanis C., Cavitation Initiation, its Development and link with Flow Turbulence in Diesel Injector Nozzles, SAE Paper 2002-01-0214, 2002.

[26] Giannadakis E., Gavaises M., Roth H. and Arcoumanis C, "Cavitation Modelling in Single-Hole Diesel Injector Based on Eulerian-Langrangian Approach", THIESEL 2004 Conference on Thermo- and FluidDynamic Processes in Diesel Engines, Valencia, September 2004.

[27]Masuda R., Fuyuto T., Nagaota M, Von Berg E., and Tatschl R., Validation of Diesel Fuel Spray and Mixture Formation from Nozzle Internal Flow Calculation, SAE paper 2005-01-2098, 2005.

Table 1. Technical data of injector

\begin{tabular}{lcc}
\hline & Cylindrical & Conical \\
\hline Average diameter in the entrance of the orifice $(\mu \mathrm{m})$ & 157 & 176 \\
Average diameter in the middle of the orifice $(\mu \mathrm{m})$ & 163 & 170 \\
Average diameter in the outlet of the orifice $(\mu \mathrm{m})$ & 163 & 165 \\
Orifice nozzle length $(\mu \mathrm{m})$ & 1000 & 1000 \\
Upper radius of the nozzle $(\mu \mathrm{m})$ & 45 & 88 \\
Bottom radius of the nozzle $(\mu \mathrm{m})$ & 45 & 88 \\
Conicity factor & 1.1 & -0.6
\end{tabular}

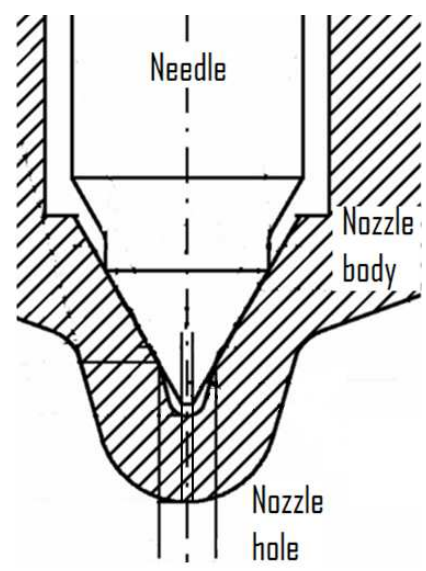

Figure 1. Configuration of the sac-type single-hole nozzle

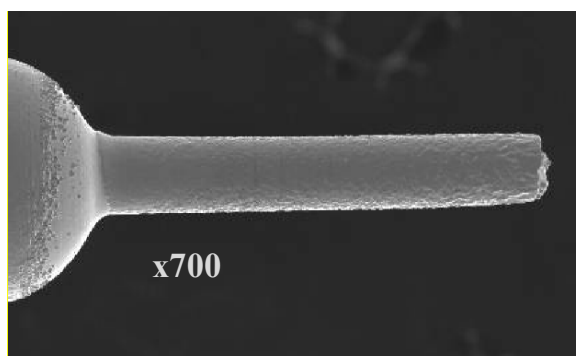

Figure 2. Characterization of the nozzle by means of silicone moulds 
a)

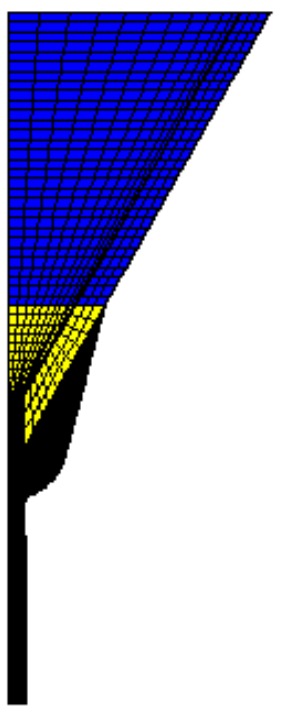

b)

Low needle lift mesh

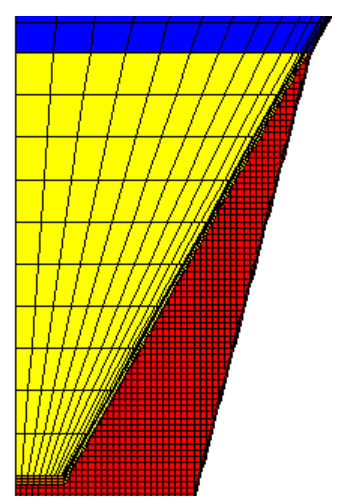

High needle lift mesh

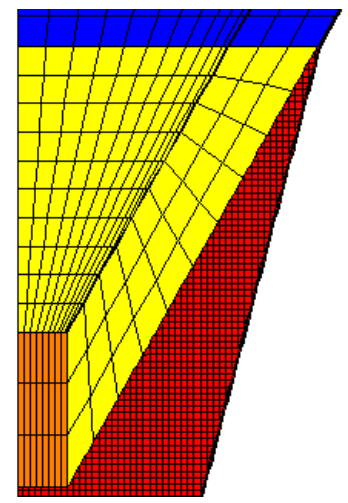

Figure 3. Images of the mesh used for the calculation a) general view at full lift, b) close-up at the hole entrance visualizing the coarse (moving) and fine (fixed) region mesh at low and high needle lift

a) Conical Nozzle

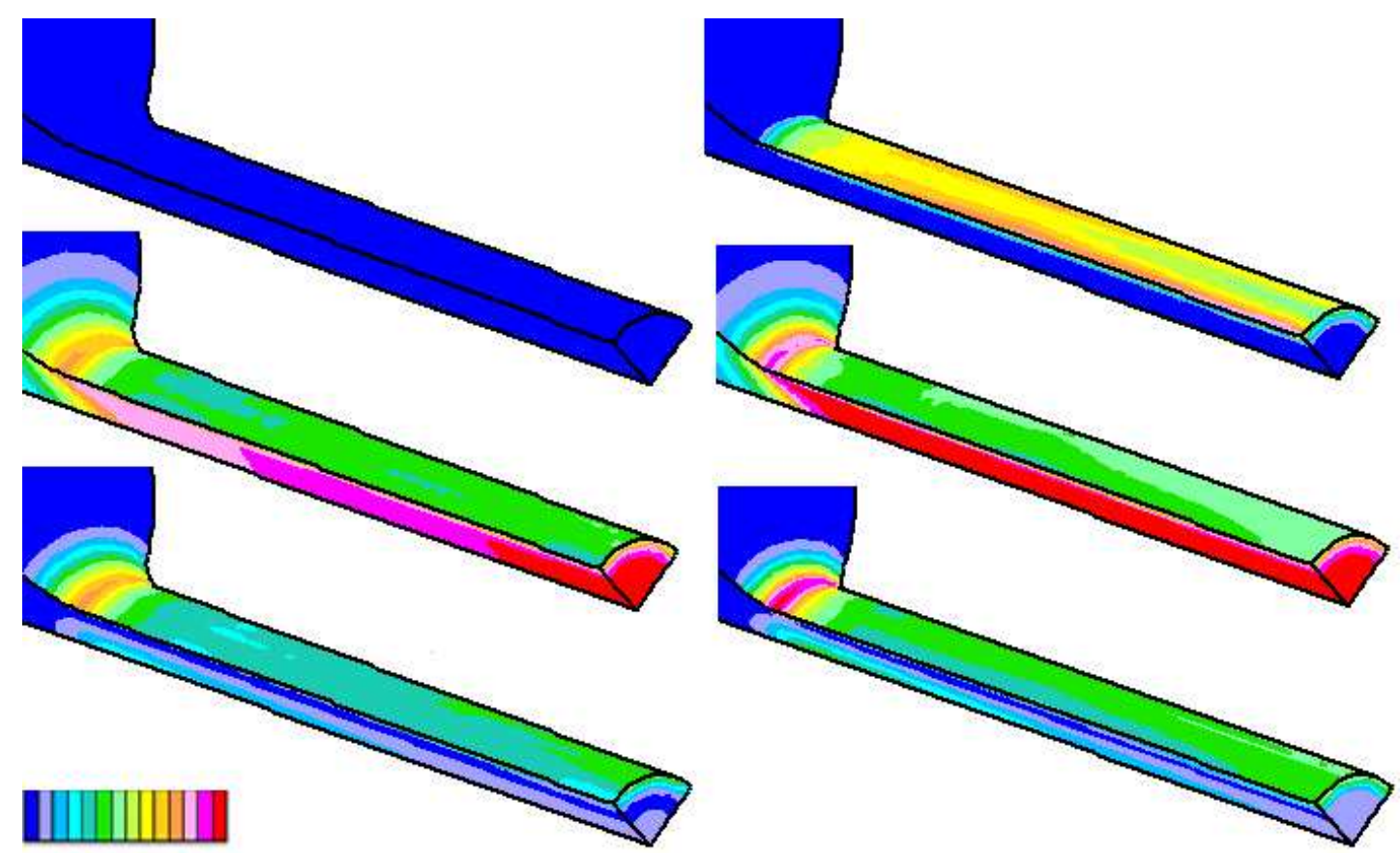

Figure 4. Representative images of volume fraction of vapor, velocity magnitude and TKE from top to bottom for a) conical and b) cylindrical nozzle hole at fully opened needle lift. Color scale: fraction of vapor: 0-1, velocity magnitude $(\mathrm{m} / \mathrm{s}): 0-600, \operatorname{TKE}\left(\mathrm{m}^{2} / \mathrm{s}^{2}\right): 0-5000$ 


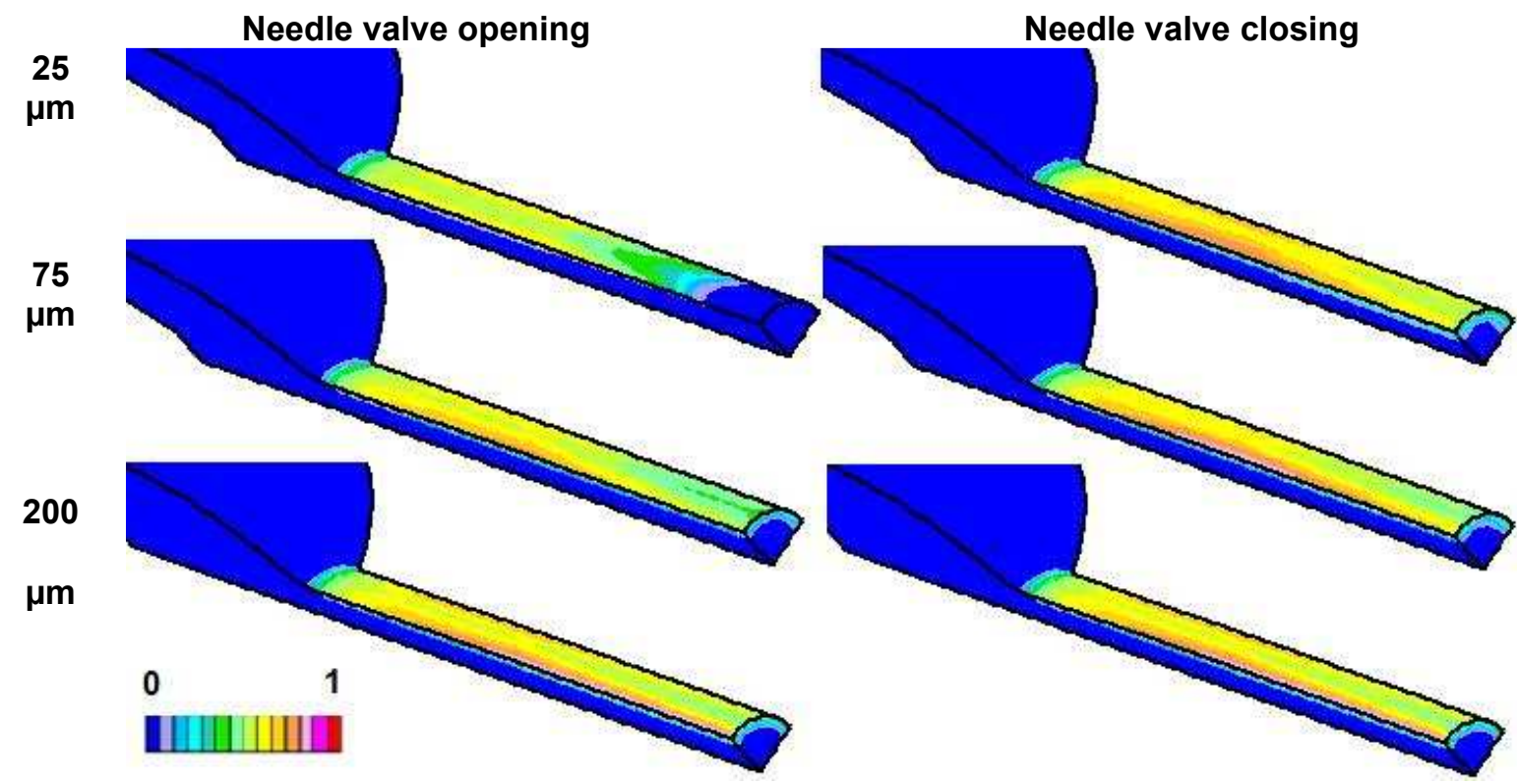

Figure 5. Predicted cavitation field at different needle lifts during the needle valve opening and closing

$\mathrm{t}=1630 \mu \mathrm{s}$

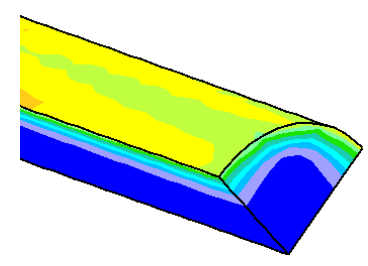

$\mathbf{t}=\mathbf{1 6 7 0 \mu s}$

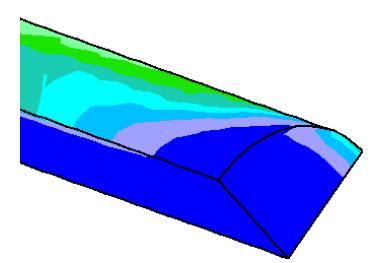

$\mathrm{t}=1640 \mu \mathrm{s}$

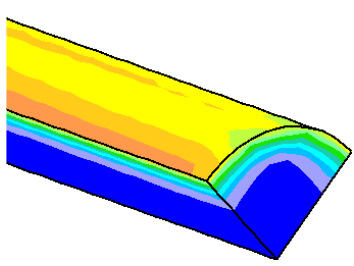

$\mathbf{t}=\mathbf{1 6 8 0} \mu \mathrm{s}$

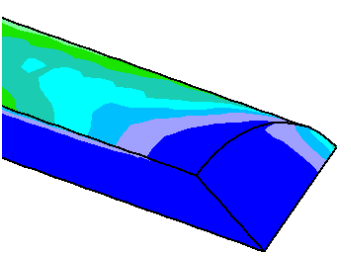

$\mathrm{t}=1650 \mu \mathrm{s}$

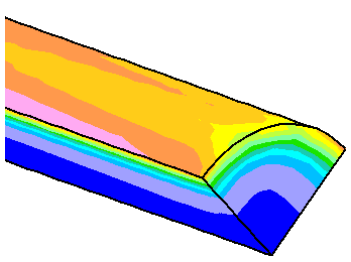

$\mathbf{t}=\mathbf{1 6 9 0} \mu \mathrm{s}$

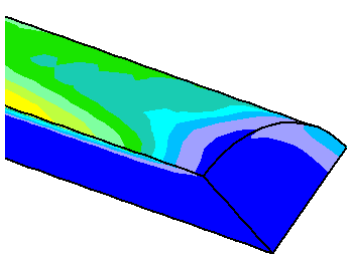

$\mathrm{t}=1660 \mu \mathrm{s}$

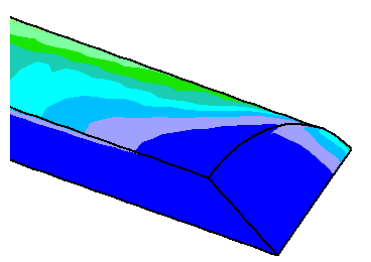

$\mathbf{t}=\mathbf{1 7 0 0} \boldsymbol{\mu s}$

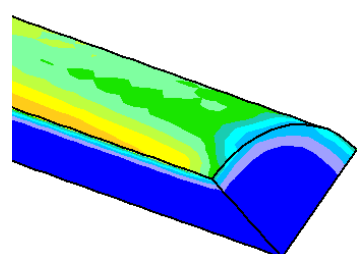

Figure 6. Temporal sequence of volume fraction of vapour showing the exit of cavitation cloud at needle closing for the cylindrical nozzle. Color scale same as in Figure 5 

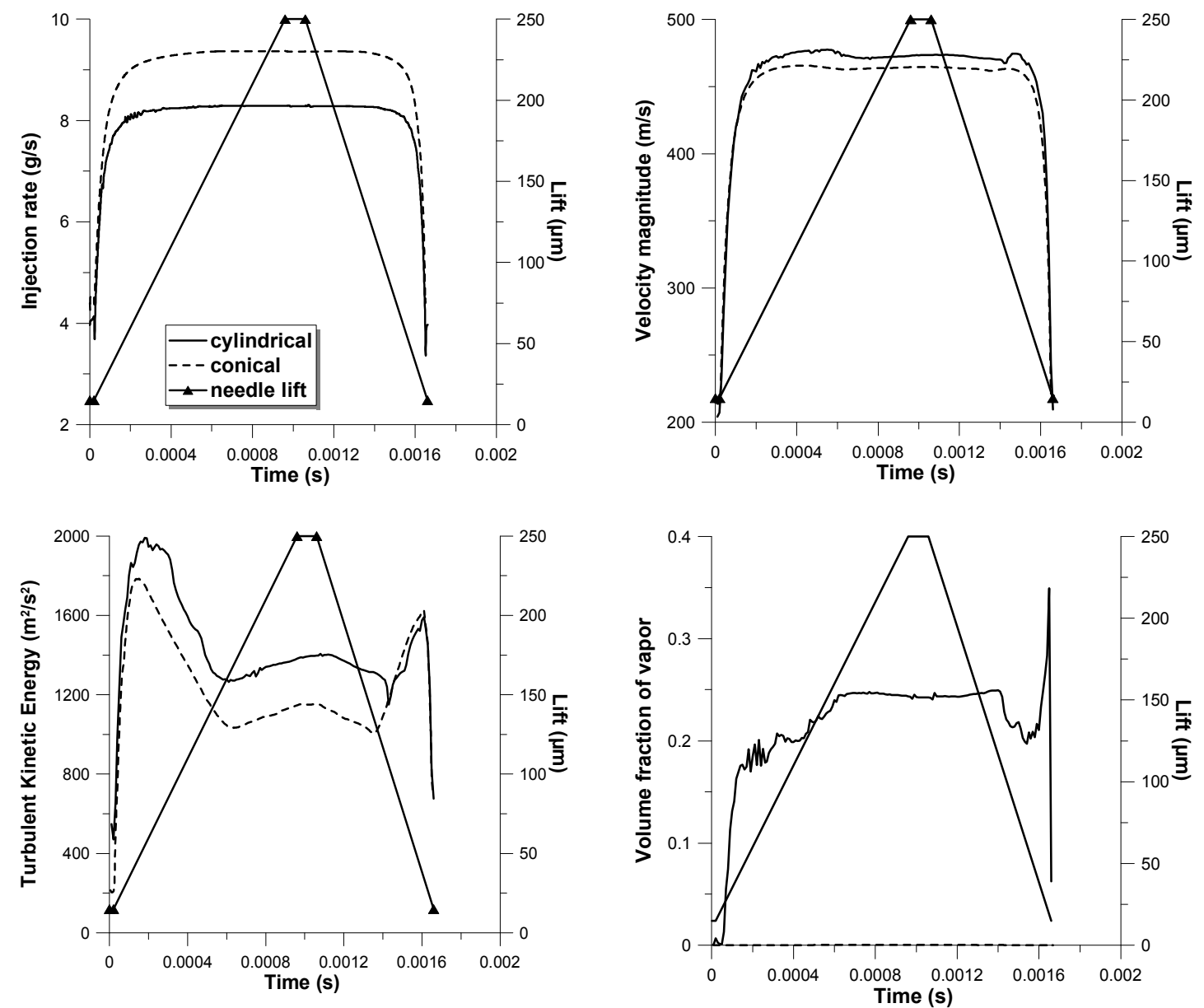

Figure 7. Instantaneous results of injection rate, mean velocity, TKE, and \% exit area occupied by vapor (volume fraction of vapor between 0.06 and 1 considered) at the exit of the nozzle during the simulated injection process 